\title{
Prospective study on prevalence of dermatological changes in patients under hemodialysis in hemodialysis units in Tanta University hospitals, Egypt
}

\author{
This article was published in the following Dove Press journal: \\ Clinical, Cosmetic and Investigational Dermatology \\ II November 2014 \\ Number of times this article has been viewed
}

\section{Basma Mourad' \\ Doaa Hegab' \\ Kamal Okasha ${ }^{2}$ \\ Sarah Rizk ${ }^{3}$}

'Dermatology and Venereology Department, ${ }^{2}$ Internal Medicine Department, Faculty of Medicine, Tanta University, ${ }^{3}$ Ministry of Health, Tanta, Egypt

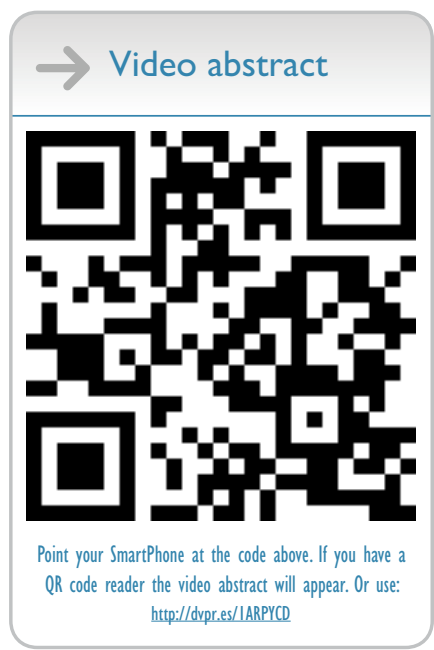

Correspondence: Doaa Hegab Dermatology and Venereology Department, Faculty of Medicine, Tanta University, El Geish Street, Tanta 3IIII, Egypt

Tel +20 I22 4500857

Email doaasalahhegab@yahoo.com
Introduction: Chronic hemodialysis patients experience frequent and varied mucocutaneous manifestations in addition to hair and nail disorders. The aim of this study was to evaluate the prevalence of dermatological changes among patients with end-stage renal disease under hemodialysis in a hemodialysis unit in Tanta University hospitals over a period of 6 months, and to evaluate the relations of these dermatological disorders with the duration of hemodialysis as well as with different laboratory parameters in these patients.

Patients and methods: Ninety-three patients with end-stage renal disease on regular hemodialysis (56 males and 37 females) were selected and included in this cross-sectional, descriptive, analytic study. Their ages ranged from 18-80 years. All patients underwent thorough general and dermatological examinations. Laboratory investigations (complete blood counts, renal and liver function tests, serum parathormone levels, serum electrolytes, alkaline phosphatase, random blood sugar, and Hepatitis $C$ virus (HCV) antibodies) were evaluated.

Results: This study revealed that most patients had nonspecific skin changes, including xerosis, pruritus, pallor, ecchymosis, hyperpigmentation, and follicular hyperkeratosis. Nail and hair changes were commonly found, especially half and half nail, koilonychia, subungal hyperkeratosis, melanonychia, onychomycosis, and brittle and lusterless hair. Mucous membrane changes detected were pallor, xerostomia, macroglossia, bleeding gums, aphthous stomatitis, and yellow sclera. There was a significant positive correlation between the presence of pruritus and serum parathormone level. There was a significant negative correlation between the presence of mucous membrane changes and hemoglobin level.

Conclusion: Nonspecific mucocutaneous manifestations are common in patients on hemodialysis, particularly xerosis, dyspigmentation, and pruritus. Early and prompt recognition and treatment of dermatological conditions in patients on dialysis may improve their quality of life.

Keywords: End-stage renal disease, skin changes, hair disorders, nail disorders

\section{Introduction}

Renal failure or end-stage renal disease (ESRD) is a condition in which the kidneys cannot fulfill their functions of discharging metabolic wastes and of maintaining the fluid and electrolyte balance. It can be divided into two stages: acute and chronic. ${ }^{1}$

In the United States, about 12\% (25 million) are estimated to have chronic kidney disease, whereas less than $0.2 \%$ have been treated by dialysis or transplantation. ${ }^{2}$ 
The prevalence of chronic kidney disease is especially high in the elderly, affecting $40 \%$ of people over the age of 70 years. ${ }^{3}$ Renal failure is a global public health problem, but the disease magnitude has been better characterized in developed countries. ${ }^{4}$

Dialysis is a treatment modality for ESRD, either hemodialysis (HD) or peritoneal dialysis. ${ }^{5,6}$ Patients on HD have a high prevalence of mucocutaneous changes because of several contributory factors, including uremia, metabolic disorders, dialysis, and side effects of immunosuppressive drugs. ${ }^{7,8}$ It is very difficult to judge whether any particular cutaneous manifestation is caused by either chronic renal failure or HD alone because many of them are associated with both of these situations. ${ }^{9}$ Skin changes in dialysis patients have been categorized as specific skin manifestations (acquired perforating dermatosis, calcific uremic arteriolopathy, bullous diseases, and nephrogenic fibrosing dermopathy) and nonspecific skin manifestations (pruritus, xerosis, nail disorders, hair disorders, pigmentary changes, purpura, oral changes, pallor, and uremic frost). ${ }^{10}$

This study aimed to evaluate the prevalence and pattern of different mucocutaneous disorders among chronic HD patients in the HD units in Tanta University hospitals and to evaluate the relationship of these dermatological disorders with the duration of HD as well as different laboratory parameters in these patients.

\section{Patients and methods}

A total of 93 adult patients attending the renal dialysis units in Tanta University hospitals for HD through a period of 6 months were included in this cross-sectional descriptive study, and a written informed consent was taken from those who agreed to participate. Patients with chronic skin diseases prior to onset of HD, patients receiving any treatment other than HD, and patients with other systemic diseases that may lead to dermatological changes were excluded.

Patients included in this study were subjected to complete history taking, thorough general and dermatological examination, and their lesions were photographed. Laboratory investigations in the form of complete blood counts, renal and hepatic functions tests, serum parathormone level, serum electrolytes, alkaline phosphatase, random blood sugar, and Hepatitis $C$ virus antibodies were collected from the most recent data in the patients' files and were repeated when necessary.

\section{Statistical analysis}

Statistical presentation and analysis was conducted using the mean, standard deviation, and chi-square test by the Statistics
Package for Social Sciences, version 18. A $P$-value less than 0.05 was considered statistically significant.

\section{Results}

The present study included 93 patients with ESRD on HD; 56 males $(60.2 \%)$ and 37 females $(39.8 \%)$, with a ratio of $1.5: 1$. Their ages ranged from 18-80 years with a mean of $50.23 \pm 14.10$ years, and the duration of HD ranged from 0.5-180 months with a mean of $38.77 \pm 10.6$ months.

The frequency distribution of different mucocutaneous, hair, and nail changes in chronic HD patients is shown in Table 1 and Figure 1. Regarding the prevalence of cutaneous changes in patients on HD, xerosis was the most common manifestation, detected in $86 \%$ of the patients, followed by hyperpigmentation in $56 \%$ (35.5\% of HD patients had hyperpigmentation on exposed parts, while $20.4 \%$ had diffuse hyperpigmentation), pruritus in $51.6 \%$, ecchymosis in $47.3 \%$, and follicular hyperkeratosis in $48.4 \%$.

Regarding hair changes, lusterless and brittle hair were most common, detected in $68.8 \%$ and $67.7 \%$ of patients,

Table I Prevalence of cutaneous changes in patients on hemodialysis

\begin{tabular}{|c|c|c|}
\hline & \multicolumn{2}{|c|}{ Patients $(n=93)$} \\
\hline & $\mathbf{n}$ & $\%$ \\
\hline \multicolumn{3}{|l|}{ Cutaneous changes } \\
\hline Xerosis & 80 & 86 \\
\hline \multicolumn{3}{|l|}{ Pruritus } \\
\hline Mild & 20 & 21.5 \\
\hline Moderate & 20 & 21.5 \\
\hline Severe & 8 & 8.6 \\
\hline Ecchymosis & 44 & 47.3 \\
\hline \multicolumn{3}{|l|}{ Hyperpigmentation } \\
\hline On exposed parts & 33 & 35.5 \\
\hline All over the body & 19 & 20.4 \\
\hline Follicular hyperkeratosis & 45 & 48.4 \\
\hline \multicolumn{3}{|l|}{ Hair changes } \\
\hline Brittle hair & 63 & 67.7 \\
\hline Lusterless hair & 64 & 68.8 \\
\hline Diffuse hair loss & 6 & 6.5 \\
\hline \multicolumn{3}{|l|}{ Nail changes } \\
\hline Half and half nail & 71 & 76.3 \\
\hline Koilonychia & 22 & 23.7 \\
\hline Subungal hyperkeratosis & 18 & 19.4 \\
\hline Melanonychia & 23 & 24.7 \\
\hline Onychomycosis & 28 & 30.1 \\
\hline Mees' line & 9 & 9.7 \\
\hline \multicolumn{3}{|l|}{ Mucous membrane changes } \\
\hline Pallor & 52 & 55.9 \\
\hline Xerostomia & 40 & 43.01 \\
\hline Macroglossia & 35 & 37.6 \\
\hline Bleeding gum & 33 & 35.4 \\
\hline Aphthous stomatitis & 10 & 10.7 \\
\hline Scleral changes & 52 & 55.9 \\
\hline
\end{tabular}




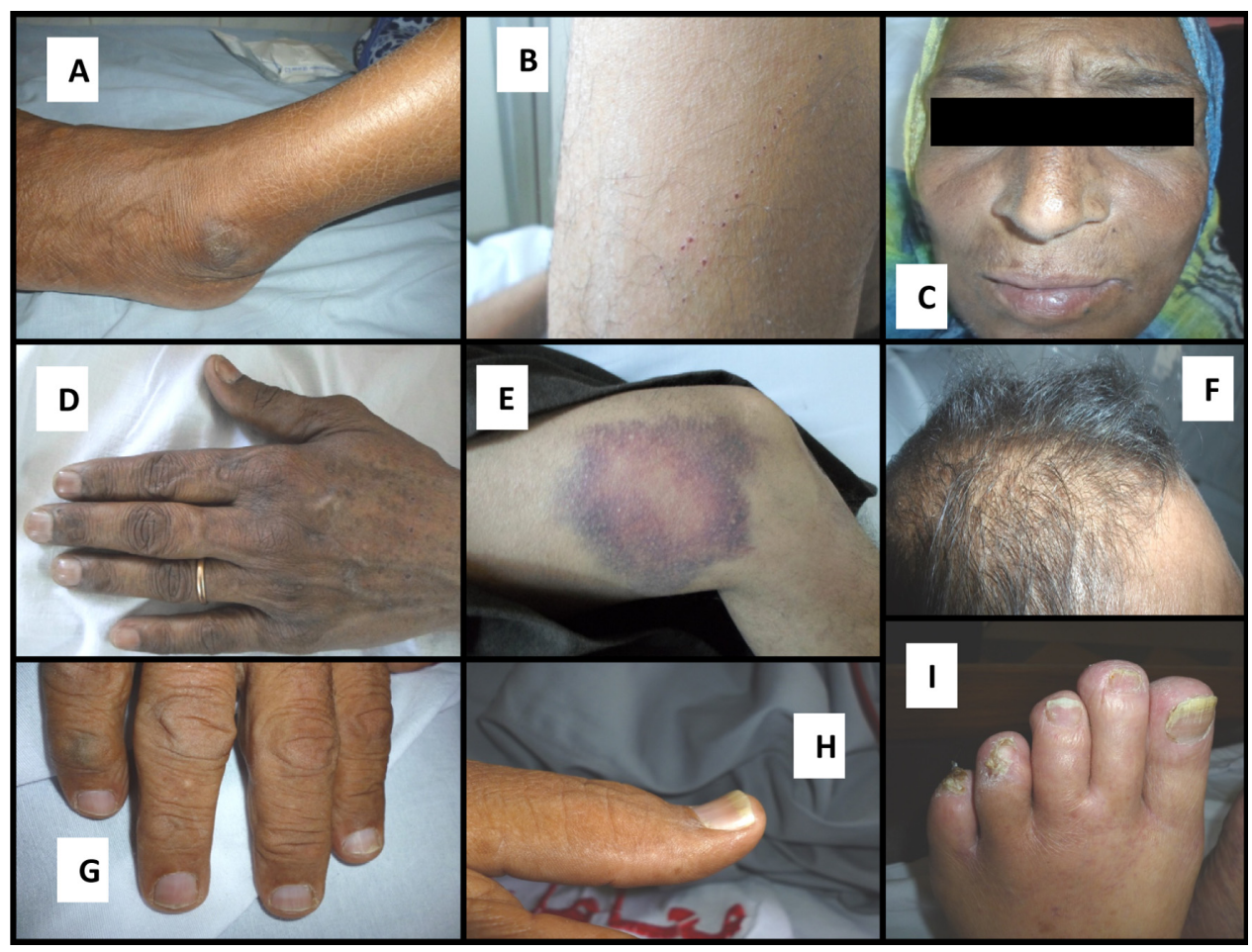

Figure I Dermatologic changes in patients on hemodialysis.

Notes: (A) Xerosis on the leg. (B) Severe pruritus with scratch marks on lower limb. (C) Hyperpigmentation on the face. (D) Hyperpigmentation of the hands with melanonychia. (E) Ecchymosis. (F) Diffuse hair loss. (G) Half and half nails. (H) Koilonychia. (I) Onychomycosis.

respectively, while $6.5 \%$ of the patients had diffuse hair loss.

For nail changes; half and half nails were the most common finding, detected in $76.3 \%$ of patients on HD, followed by onychomycosis in $30.1 \%$, melanonychia in $24.7 \%$, koilonychia in $23.7 \%$, and subungal hyperkeratosis in $19.4 \%$, while Mees' lines was the least common finding $(9.75 \%)$.

Among mucous membrane changes, pallor of oral mucosa and yellow sclera were the most common findings, detected in $55.9 \%$ of HD patients. Xerostomia was present in $43.01 \%$ of patients, macroglossia in $37.6 \%$, bleeding gums in $35.4 \%$, and $10.7 \%$ of patients had aphthous stomatitis.

In the current study, there were statistically insignificant positive correlations between the presence of skin, hair, nail, and mucous membrane changes and the duration of HD (Table 2).

Correlations between skin manifestations in patients on HD and their laboratory investigations showed a statistically significant positive correlation between the presence of cutaneous changes (pruritus in particular) and serum parathormone level (Table 3). On the other hand, hair and nail changes showed statistically nonsignificant correlations with the laboratory findings of HD patients. Meanwhile, a statistically significant negative correlation was detected between the presence of mucous membrane changes and hemoglobin level (Table 3).

\section{Discussion}

Skin problems are common and diverse in patients with ESRD, especially in those on HD, and they usually have no consistent association with age, sex, race, or precipitating disease for renal failure. They could predate the onset of dialysis or could be precipitated by it. $9,11,12$

In the present study, all HD patients showed one or more dermatological lesion, and these results were in agreement with results of Shah et al ${ }^{13}$ who reported that all patients of chronic kidney disease on maintenance HD in their study had at least one of the dermatological changes. In another study performed on 300 adult patients on HD, it was reported that cutaneous changes were present in $96 \%$ of them. ${ }^{12}$ In the current study, there was no statistically significant relation between the duration of HD and the

Table 2 Correlation between skin, hair, nail, and mucous membrane changes in patients on hemodialysis and duration of hemodialysis

\begin{tabular}{lll}
\hline & \multicolumn{2}{l}{ Duration of hemodialysis } \\
\cline { 2 - 3 } & $\boldsymbol{r}$ & $\boldsymbol{P}$-value \\
\hline Skin manifestations & 0.014 & 0.225 \\
Hair changes & 0.152 & 0.390 \\
Nail changes & 0.096 & 0.523 \\
Mucous membrane changes & 0.031 & 0.224 \\
\hline
\end{tabular}


Table 3 Correlation between skin manifestations and hair, nail, and mucous membrane changes in patients on hemodialysis and their laboratory investigations

\begin{tabular}{|c|c|c|c|c|c|c|c|c|}
\hline \multirow[t]{2}{*}{ Laboratory investigations } & \multicolumn{2}{|c|}{$\begin{array}{l}\text { Skin } \\
\text { manifestations }\end{array}$} & \multicolumn{2}{|c|}{ Hair changes } & \multicolumn{2}{|c|}{ Nail changes } & \multicolumn{2}{|c|}{$\begin{array}{l}\text { Mucous membrane } \\
\text { changes }\end{array}$} \\
\hline & $r$ & $P$-value & $r$ & $P$-value & $r$ & $P$-value & $r$ & $\overline{P \text {-value }}$ \\
\hline \multicolumn{9}{|l|}{ Complete blood count } \\
\hline Hemoglobin level (gm/dL) & -0.339 & 0.011 & -0.225 & 0.048 & -0.384 & 0.014 & -0.415 & $0.00 I^{*}$ \\
\hline Leukocytic count (cells/mm³) & 0.110 & 0.225 & 0.038 & 0.719 & 0.198 & 0.057 & 0.064 & 0.220 \\
\hline Platelet count (cells/mm³) & -0.115 & 0.225 & -0.056 & 0.594 & -0.821 & 0.436 & -0.123 & 0.142 \\
\hline \multicolumn{9}{|l|}{ Renal function tests } \\
\hline Blood urea nitrogen (mg/dL) & 0.109 & 0.209 & 0.196 & 0.158 & $0.24 I$ & 0.247 & 0.225 & 0.269 \\
\hline Creatinine (mg/dL) & 0.062 & 0.582 & 0.087 & 0.407 & 0.115 & 0.633 & 0.118 & 0.774 \\
\hline \multicolumn{9}{|l|}{ Serum electrolytes } \\
\hline $\mathrm{Ca}^{++}(\mathrm{mmol} / \mathrm{L})$ & -0.075 & 0.896 & -0.054 & 0.606 & -0.080 & 0.852 & -0.027 & $0.44 I$ \\
\hline $\mathrm{P}^{3-}(\mathrm{mmol} / \mathrm{L})$ & 0.133 & 0.556 & 0.146 & 0.164 & 0.028 & 0.411 & 0.030 & 0.777 \\
\hline $\mathrm{Na}^{+}(\mathrm{mmol} / \mathrm{L})$ & 0.080 & 0.147 & 0.023 & 0.524 & 0.243 & 0.019 & 0.007 & 0.945 \\
\hline $\mathrm{K}^{+}(\mathrm{mmol} / \mathrm{L})$ & 0.027 & 0.528 & 0.140 & 0.182 & 0.006 & 0.956 & 0.136 & 0.201 \\
\hline Parathormone $(\mathrm{pg} / \mathrm{mL})$ & 0.441 & $0.010^{*}$ & 0.219 & 0.052 & 0.045 & 0.668 & 0.010 & 0.953 \\
\hline Serum alkaline phosphatase (U/L) & 0.029 & 0.983 & 0.144 & 0.558 & 0.039 & 0.523 & 0.075 & $0.74 I$ \\
\hline
\end{tabular}

Note: *Statistically significant.

prevalence of dermatological changes in HD patients; these results were in agreement with those of Hajheydari et al. ${ }^{8}$

Xerosis was the most prevalent skin manifestation, was detected in $86 \%$ of HD patients in the current study, and the extremities were the most affected site, especially the lower limbs. Xerosis has been reported to be prevalent in 54\% to $91 \%$ of patients on HD in various studies. ${ }^{12,14-18}$ Hajheydari et $\mathrm{al}^{8}$ found xerosis in only $23 \%$ of HD patients. This difference might be attributed to environmental exposures and climatic factors; the present study was done in winter, which aggravates the condition of cutaneous dryness. Alteration of vitamin A metabolism, glycerol deficiency with skin dehydration, barrier dysfunction, chemically induced irritation, functional abnormalities of eccrine sweat glands, and high doses of diuretics may be responsible factors for xerosis in HD patients. ${ }^{12,13}$

In the present study, $56 \%$ of patients had hyperpigmentation on sun-exposed parts of the body, or generalized all over the body. Udayakumar et al ${ }^{14}$ reported this finding in $43 \%$ of their HD patients, while Mirza et al $^{12}$ reported that hyperpigmentation was found in $54.3 \%$ of their patients on HD. Diffuse hyperpigmentation could be attributed to increased levels of $\beta$-melanocyte stimulating hormone as a result of its inadequate excretion through kidney and dialysis. ${ }^{18}$ Many HD patients show a yellowish tinge of dyspigmentation, which could be attributed to excess deposition of two major pigments, namely carotenoids and lipochromes, in the epidermis and subcutaneous tissue. ${ }^{19}$ The use of high-flux HD or hemodiafiltration may increase the clearance of all the abovementioned substances, and thus improves the dyspigmentation. ${ }^{20}$

Another common cutaneous manifestation in this study was pruritus, with a prevalence rate of $51.6 \%$. This condition may be attributed to dry skin and secondary hyperparathyroidism, which were very common in our patients. In the different published studies, the prevalence of pruritus ranged between $19 \%$ and $90 \%$, and it has been reported that pruritus in HD patients is of variable severity, but mostly severe and disturbing sleep and daily activity. ${ }^{14-16,21,22}$ Sultan et al ${ }^{17}$ reported that pruritus was found in $55 \%$ of their HD patients. They concluded that HD patients have lower water content in the stratum corneum in addition to retention of middle molecules (B2 microglobulin, parathyroid hormone, and glycosylation end products), which are thought to cause pruritus. Others suggested that the cause of pruritus was due to increased serum histamine levels, which may be due to allergic sensitization to dialyzer membrane components and to impaired renal excretion of histamine or due to inadequate dialysis, anemia, peripheral neuropathy, and/ or uremic toxins. ${ }^{8,23}$ In another study, pruritus began after starting HD in about $50 \%$ of the patients. ${ }^{8}$ Several previous studies have reported that the serum parathormone level in HD patients with pruritus was significantly higher than in those without pruritus. ${ }^{24-26}$ However, Ståhle-Bäckdahl et $\mathrm{a}^{26}$ found no association between the severity of pruritus and the serum parathormone levels. On the contrary, other studies have reported the absence of significant association between pruritus and serum parathormone levels. ${ }^{27-29}$ 
Ecchymosis was found in $47.3 \%$ of patients in the current study; this may be explained by the use of heparin during dialysis. Peres et $\mathrm{al}^{30}$ reported that ecchymosis was present in $60 \%$ of their patients on HD. They observed that easy bruisability and increased skin fragility were worse in the patients who were on dialysis for a longer time. On the other hand, Udayakumar et a ${ }^{14}$ reported ecchymosis in only $9 \%$ of their HD patients; they attributed ecchymosis to defects in platelet function, use of heparin during dialysis, and increased vascular fragility.

As regards follicular hyperkeratosis, it was found in $48.4 \%$ of patients in the present study, mostly in females, and the most affected site was the lower limbs. While Sultan et $\mathrm{al}^{17}$ reported that follicular hyperkeratosis was found only in $10 \%$ of their HD patients, they explained that this is due to increased keratinization of the skin. The difference could be attributed to the higher existence of xerosis in the patients in the present study.

More than $70 \%$ of the patients in the current study had hair changes. The results of the present study were in agreement with Mirza et al, ${ }^{12}$ who reported that hair changes were present in $56.6 \%$ of their HD patients. Sultan et al ${ }^{17}$ reported that hair changes were detected in $47 \%$ of their HD patients. Udayakumar et $\mathrm{al}^{14}$ reported that $16 \%$ of their HD patients had lusterless hair, and they explained hair problems by presence of anemia, decreased sebum secretion, and secondary hyperparathyroidism. The higher existence of hair changes in the present study could be attributed to higher incidence of iron deficiency anemia, disturbed parathormone level, or psychic impacts of ESRD and dialysis with neglect of hair care.

The prevalence of half and half nails, a characteristic finding of chronic renal failure, was $76.3 \%$ in patients in the present study, compared to $1.4 \%{ }^{18}$ in the general population. Udayakumar et al, ${ }^{14}$ Mirza et $a l,{ }^{12}$ and Sultan et al ${ }^{17}$ found half and half nails were found in $21 \%, 36.75 \%$, and $28 \%$ respectively, of their patients on HD.

Koilonychia was found in $23.7 \%$ of patients in the present study. This may be due to higher incidence of anemia in our patients. Koilonychia has been reported in $18 \%-93 \%$ of patients with ESRD in various studies. ${ }^{14,17}$ Subungal hyperkeratosis was found in $19.4 \%$ of HD patients in the present study, while onychomycosis was found in $30.1 \%$. Hajheydari et al did not find any patients with fungal nail infection in their study, ${ }^{8}$ while Naderi et a ${ }^{15}$ reported onychomycosis in $1.9 \%$.

Melanonychia was a common finding in our HD patients $(24.7 \%)$. This can be attributed to deposition of melanin in the nail bed as a result of failure of the kidneys to excrete $\beta$-melanocyte stimulating hormone. Sultan et $\mathrm{al}^{17}$ found brown nails in only $6 \%$ of their HD patients. The difference could be attributed to the different study populations and their tendency to pigmentation.

Mucosal disorders were very common in our study patients, and the high incidence of pallor among our patients is a reflection of the high rate of anemia among them. Thomas et $\mathrm{al}^{31}$ have also reported that anemia was a common problem in their ESRD patients; $45.45 \%$ of them had pallor. Deficient erythropoietin production by the failing kidneys and dietary deficiencies of iron, folic acid, and vitamin B12 contribute to anemia. ${ }^{32}$ Hajheydari et $\mathrm{al}^{8}$ have reported a prevalence of mucosal lesions in $24 \%$ of their patients, with the most common finding being furred tongue (8\%), while Yaghubi et al reported a prevalence of mucosal disorders in $29 \%$ of their patients, with gingivitis being the most common finding. ${ }^{16}$

Aphthous stomatitis was found in $10.7 \%$ of patients in the current study, which may be due to elevated blood urea level and bad oral hygiene. This finding is similar to the findings of Sultan et al, ${ }^{17}$ who reported the presence of oral ulcers in $9 \%$ of their HD patients. On the other hand, Udayakumar et $\mathrm{al}^{14}$ reported ulcerative stomatitis in $29 \%$ of their patients; this high incidence was attributed by the authors to the intake of alcohol, spices, hot food, and tobacco smoking, which are precipitating factors for ulcerative stomatitis.

Yellow sclera was found in $55.9 \%$ of the patients in the current study, which may be due to impaired liver function and hypercarotenemia.

Various other dermatoses, such as acquired perforating dermatoses, calcific uremic arteriopathy, bullous dermatoses of HD, nephrogenic fibrosing dermopathy, and arteriovenous shunt dermatitis, have been frequently reported in previous publications, but they were not detected in any of our studied HD patients, neither during the period of the study (6 months) nor in their past history.

There were nonsignificant correlations between the presence of mucocutaneous, hair, and nail changes and laboratory findings in HD patients in the present study. This could be attributed to the frequent changes and instability of these laboratory test results from time to time according to the circumstances (effect of dialysis sessions, meals, drugs, and other factors). However, there was a positive correlation between pruritus and serum parathormone level, and a negative correlation between mucous membrane changes and hemoglobin level. 
In conclusion, we reported that nonspecific skin manifestations were very frequent in patients on HD; xerosis was the most frequent, followed by half and half nails, lusterless hair, brittle hair, hyperpigmentation, pallor of oral mucosa and yellow sclera, pruritus, follicular hyperkeratosis, ecchymosis, xerostomia, macroglossia, bleeding gums, onychomycosis, melanoychia, koilonychia, subungal hyperkeratosis, aphthous stomatitis, and Mees' lines. With the development of HD techniques, the life expectancy of uremic patients has increased, giving time for more and newer cutaneous changes to appear.

Based on the results of the current study, larger randomized studies are recommended to determine the accurate prevalence of cutaneous manifestations in patients on HD in Egypt. Patients on HD should apply emollients regularly, aiming to decrease xerosis and subsequent pruritus, and they should receive iron supplements to avoid anemia. In addition, patients on HD should avoid sunlight and apply sunscreens to avoid hyperpigmentation.

\section{Disclosure}

The authors report no conflicts of interest in this work.

\section{References}

1. Yürügen B. Chronic renal failure, nursing, diagnosis and intervention. EDTNA ERCA J. 2002;28(1):13-15, 20.

2. Coresh J, Selvin E, Stevens LA, et al. Prevalence of chronic kidney disease in the United States. JAMA. 2007;298(17):2038-2047.

3. Levey AS, Stevens LA, Coresh J. Conceptual model of CKD: applications and implications. Am J Kidney Dis. 2009;53(3 Suppl 3): S4-S16.

4. Pugsley D, Norris KC, Garcia-Garcia G, Agodoa L. Global approaches for understanding the disproportionate burden of chronic kidney disease. Ethn Dis. 2009;19(1 Suppl 1):S1-S1.

5. Ikizler TA, Schulman G. Hemodialysis: techniques and prescription. Am J Kidney Dis. 2005;46(5):976-981.

6. Kurella M, Chertow GM. Dialysis session length ("t") as a determinant of the adequacy of dialysis. Semin Nephrol. 2005;25(2):90-95.

7. Tajbakhsh R, Dehghan M, Azarhoosh R, et al. Mucocutaneous manifestations and nail changes in patients with end-stage renal disease on hemodialysis. Saudi J Kidney Dis Transpl. 2013;24(1):36-40.

8. Hajheydari Z, Makhlough A. Cutaneous and mucosal manifestations in patients on maintenance hemodialysis: a study of 101 patients in Sari, Iran. Iran J Kidney Dis. 2008;2(2):86-90.

9. Sanai M, Aman S, Nadeem M, Kazmi AH. Dermatologic manifestations in patients of renal disease on hemodialysis. J Pakistan Assoc Dermatol. 2010;20:163-168.

10. Abdelbaqi-Salhab M, Shalhub S, Morgan MB. A current review of the cutaneous manifestations of renal disease. J Cutan Pathol. 2003;30(9):527-538.

11. Shah A, Hada R, Kayastha BM. Dermatological disorders in chronic kidney disease with and without maintenance hemodialysis. JNMA J Nepal Med Assoc. 2013;52(190):365-371.
12. Mirza R, Wahid R, Talat H. Dermatological manifestations in chronic renal failure patients on haemodialysis. JLUMHS. 2012;11(1):24-28.

13. Shah A, Hada R, Kayastha BM. Dermatological disorders in chronic kidney disease with and without maintenance hemodialysis. JNMA J Nepal Med Assoc. 2013;52(190):365-371.

14. Udayakumar P, Balasubramainan S, Ramalingam KS, Lakshmi MC, Srinivas CR, Mathew AC. Cutaneous manifestatious in patients with chronic renal failure on hemodialysis. Indian J Dermatol Venereal Leprol. 2006;72:119-125.

15. Naderi N, Mahdavi-Mazdeh M, Firouz A, Heydari Seraj M. Cutaneous manifestations of end stage renal disease under hemodialysis in hemodialysis ward at Imam Khomeini hospital in Tehran in 2003. Iran J Dermatol. 2005;6:489-495.

16. Yaghubi R, Niloufar S, Latifee SM. Cutaneous manifestations of end stage renal disease under hemodialysis. Iran J Dermatol. 2002;5:29-34.

17. Sultan MM, Mansour HH, Wahby IM, Houdery AS. Cutaneous manifestations in Egyptian patients with chronic renal failure on regular haemodialysis. J Egypt Women Dermatol Soc. 2010;7(1):49-55.

18. Deshmukh SP, Sharma YK, Dash K, Chaudhari NC, Deo KS. Clinicoepidemiological study of skin manifestations in patients of chronic renal failure on hemodialysis. Indian Dermatol Online J. 2013;4(1):18-21.

19. Headley CM, Wall B. ESRD-associated cutaneous manifestations in a hemodialysis population. Nephrol Nurs J. 2002;29(6):525-527, 531-539.

20. Moon SJ, Kim DK, Chang JH, et al. The impact of dialysis modality on skin hyperpigmentation in haemodialysis patients. Nephrol Dial Transplant. 2009;24(9):2803-2809.

21. Szepietowski JC, Sikora M, Kusztal M, Salomon J, Magott M, Szepietowski T. Uremic prurtis: a clinicl study of maintenance hemodialysis patients. J Dermatol. 2002;29(10):621-627.

22. Zucker L, Kosiporitch G, David M, Gafter U, Boner G. Prevalence and characterization of uremic pruritis in patients undergoing hemodialysis: uremic pruritis is still a major problem for patients with end-stage renal disease. J Am Acad Dermatol. 2003;49(5);842-846.

23. Tsukahara K, Takema Y, Moriwaki S, Fujimura T, Imokawa G. Dermal fluid translocation is an important determinant of the diurnal variation in human skin thickness. Br J Dermatol. 2001;145(4):590-596.

24. Narita I, Alchi B, Omori K, et al. Etiology and prognostic significance of severe uremic pruritus in chronic hemodialysis patients. Kidney Int. 2006;69(9):1626-1632.

25. Yazdanpanah M, Mojahedi M, Ebrahimi Rad M, Birjandi M. Cutaneous manifestations in hemodialysis patients with chronic renal failure. Mashhad Univ Med Sci J. 2006;25:92, 509.

26. Ståhle-Bäckdahl M, Hagermark O, Lins LE. Pruritus in patients on maintenance hemodialysis. Acta Med Scand. 1988;224(1):55-60.

27. Szepietowski JC. Selected elements of the pathogenesis of pruritus in hemodialysis patients: My own study. Med Sci Monit. 1996;2:343-347.

28. Akhyani M, Ganji MR, Samadi N, Khamesan B, Daneshpazhooh M. Pruritus in hemodialysis patients. BMC Dermatol. 2005;5:7.

29. Tajbakhsh R, Joshaghani HR, Bayzayi F, Haddad M, Qorbani M. Association between pruritus and serum concentrations of parathormone, calcium and phosphorus in hemodialysis patients. Saudi J Kidney Dis Transpl. 2013;24(4):702-706.

30. Peres LA, Passarini SR, Branco MF, Kruger LA. [Skin lesions in chronic renal dialysis]. J Bras Nefrol. 2014;36(1):42-47. Portuguese.

31. Thomas EA, Pawar B, Thomas A. A prospective study of cutaneous abnormalities in patients with chronic kidney disease. Indian J Nephrol. 2012;22(2):116-120.

32. Specchio F, Carboni I, Chimenti S, Tamburi F, Nistico' S. Cutaneous manifestations in patients with chronic renal failure on hemodialysis. Int J Immunopathol Pharmacol. 2014;27(1):1-4. 


\section{Publish your work in this journal}

Clinical, Cosmetic and Investigational Dermatology is an international, peer-reviewed, open access, online journal that focuses on the latest clinical and experimental research in all aspects of skin disease and cosmetic interventions. All areas of dermatology will be covered; contributions will be welcomed from all clinicians and basic science researchers globally. This journal is indexed on CAS. The manuscript management system is completely online and includes a very quick and fair peer-review system, which is all easy to use. Visit http://www.dovepress.com/testimonials.php to read real quotes from published authors.

Submit your manuscript here: http://www.dovepress.com/clinical-cosmetic-and-investigational-dermatology-journal 